\title{
Theoretical Aspects of a Surface Electrode Reaction Coupled with Preceding and Regenerative Chemical Steps: Square-wave Voltammetry of a Surface CEC' Mechanism
}

\author{
Pavlinka Kokoskarova $^{[a]}$ and Rubin Gulaboski*[a]
}

\begin{abstract}
Large number of lipophilic substances, whose electrochemical transformation takes place from adsorbed state, belong to the class of so-called "surface-redox reactions". Of these, especially important are the enzymatic redox reactions. With the technique named "protein-film voltammetry" we can get insight into the chemical features of many lipophilic redox enzymes. Electrochemical processes of many redox adsorbates, occurring at a surface of working electrode, are very often coupled with chemical reactions. In this work, we focus on the application of square-wave voltammetry (SWV) to study the theoretical features of a surface electrode reaction coupled with two chemical steps. The starting electroactive form $\mathrm{Ox}_{(\mathrm{ads})}$ in this mechanism gets initially generated via preceding chemical reaction. After undergoing redox transformation at the working electrode, $\mathrm{Ox}_{(\mathrm{ads})}$ species got additionally regenerated via chemical reaction of electrochemically generated product $\operatorname{Red}_{(\mathrm{ads})}$
\end{abstract}

with a given substrate $\mathrm{Y}$. The theory of this so-called surface $C E C^{\prime}$ ' mechanism is presented for the first time under conditions of square-wave voltammetry. While we present plenty of calculated voltammograms of this complex electrode mechanism, we focus on the effect of rate of regenerative (catalytic) step to simulated voltammograms. We consider both, electrochemical reactions featuring moderate and fast electron transfer. The obtained voltammetric patterns are very specific, having sometime hybrid-like features of voltammograms as typical for CE, EC and EC' mechanisms. We give diagnostic criteria to recognize this complex mechanism in SWV, but we also present hints to access the kinetic and thermodynamic parameters relevant to both chemical steps, and the electrochemical reaction, too. Indeed, the results presented in this work can help experimentalists to design proper experiments to study chemical features of important lipophilic systems.

Keywords: surface redox reactions - CE mechanism - EC' mechanism - kinetics of chemical reactions $\cdot$ square-wave voltammetry.

\section{Introduction}

In the last 40 years, voltammetry is recognized as a cheap, simple and powerful electrochemical technique that enables insight into the chemistry of many important substances [1-6]. Valuable theories of many simple and complex electrochemical mechanisms are presented under conditions of various voltammetric techniques in wellrecognized works [1-56]. Many classes of lipophilic compounds undergo electrochemical transformation at working electrodes that can be described with the theories of so-called "surface electrode mechanisms" [1-13,2529,31-41,44-47,49,52]. The "protein-film voltammetry", which is a powerful electrochemical methodology designed to study chemistry of lipophilic redox enzymes [7,57-60], also belongs to the family of surface redox reactions. Electrochemical reactions with coupled chemical reactions are very important systems, because they can give valuable information about chemical features of many substances [1-32,35-54]. The determination of kinetics and thermodynamics parameters linked to certain chemical interactions give information about the rate of chemical reactivity and stability of important "surfaceactive" substances [1-6]. Indeed, recognizing the nature of particular electrode mechanism is a crucial step in order to apply defined methodologies for the determination of relevant kinetics and thermodynamics parameters. In the last 3 decades, our group $[4,5,7-38,49,54,55]$ and others [1-3,6,39-53] provided valuable theoretical methodologies in SWV to deal with these problems, even for very complex electrochemical mechanisms. In this work, we focus on specific surface electrochemical reaction, in which both electroactive participants, which are firmly immobilized at the surface of working electrode, are involved in different type of chemical reactions. While the starting redox active form gets created via a preceding reversible chemical reaction, the electrochemically generated redox product undergoes irreversible (catalytic) chemical reaction that contributes to regeneration of the starting electroactive material. The abbreviation of this mechanism is a "surface CrevEC" " ("rev" stands for reversible) or simply "surface CEC" mechanism". This

\footnotetext{
[a] P. Kokoskarova, R. Gulaboski

Faculty of Medical Sciences, Goce Delcev University, Stip, Macedonia

E-mail: rubin.gulaboski@ugd.edu.mk
}

Supporting information for this article is available on the WWW under https://doi.org/10.1002/elan.201900491 
mechanism has not been considered theoretically so far in the literature under voltammetric conditions, although one finds several experimental works related to this mechanism [61-63]. Commonly, this mechanism is met by surface redox reactions of many coordinative complexes, whose dissociation provides starting material for the electrochemical reaction. We explore square-wave voltammetry as a working technique due to its superior features in respect to speed, and its ability for significant discrimination of charging currents [4-6]. Moreover, SWV allows inspection of three current components independently, i.e. the forward, the backward and the net SWV currents $[1,2,4-6]$. These features provide more degrees of freedoms to the experimentalists in evaluating important physical parameters by using SWV.

\section{Theoretical Model}

We consider in this theoretical work a so-called "surface CEC' mechanism" under conditions of square-wave voltammetry. This complex electrode mechanism comprises an electrochemical reaction " $\mathrm{E}$ " that is coupled by one reversible preceding chemical reaction " $\mathrm{C}$ " and with an irreversible (follow up) regenerative chemical step C'. The entire mechanism can be described by following reaction scheme.

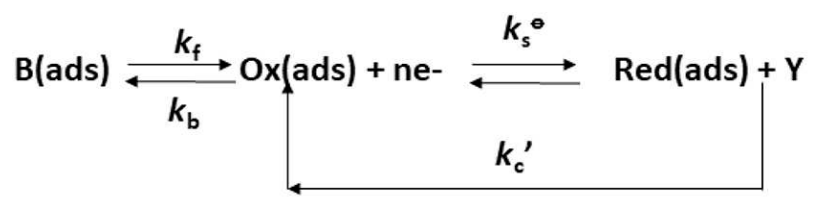

In the mathematical model, we assume that the initial amount of starting electroactive material $\mathrm{Ox}_{(\mathrm{ads})}$ is generated via chemical reaction (commonly dissociation) of compound B. At the beginning of the experiment, only species "B" are present in the voltammetric cell. Moreover, we assume that $\mathrm{B}_{(\mathrm{ads})}$ species are strongly adsorbed in a form of monolayer at the surface of working electrode. We also suppose that $\mathrm{B}_{(\mathrm{ads})}$ species do not show electrochemical activity in the range of applied potentials. In addition, we assume that no interactions occur between all adsorbed species at the working electrode. The electrode transformation (reduction) of $\mathrm{Ox}_{(\mathrm{ads})}$ produces $\operatorname{Red}_{(\mathrm{ads})}$ electrochemically active species, which react selectively with "Y" substrate in a way of regenerating $\mathrm{Ox}_{(\mathrm{ads})}$. We suppose that there is no chemical reaction between " $\mathrm{Y}$ " and $\mathrm{B}_{(\mathrm{ads})}$ species, since any type of chemical reaction between $\mathrm{Y}$ and $\mathrm{B}$ can turn the CEC' mechanism into a more complex one. We also consider that "Y" species do not show electrochemical activity in the range of applied potentials. Both electrochemically active species $\mathrm{Ox}_{(\mathrm{ads})}$ and $\mathrm{Red}_{(\mathrm{ads})}$ are firmly adsorbed at the working electrode surface, and there is no mass transfer taking place via diffusion. Mathematically, this electrode mechanism is described with following equations:

$$
\begin{aligned}
& (\mathrm{d} \Gamma(\mathrm{B}) / \mathrm{d} t)=k_{\mathrm{b}} \Gamma(\mathrm{Ox})-k_{\mathrm{f}} \Gamma(\mathrm{B}) \\
& (\mathrm{d} \Gamma(\mathrm{Ox}) / \mathrm{d} t)=[-I /(n F S)]-k_{\mathrm{b}} \Gamma(\mathrm{Ox})+k_{\mathrm{f}} \Gamma(\mathrm{B})+k_{\mathrm{c}}{ }^{\prime} \\
& \Gamma(\mathrm{Red}) \\
& (\mathrm{d} \Gamma(\mathrm{Red}) / \mathrm{d} t)=[I /(n F S)]-k_{\mathrm{c}}{ }^{\prime} \Gamma(\mathrm{Red})
\end{aligned}
$$

The differential equations (1-3) have been solved under following conditions:

$$
\begin{aligned}
& t=0 ; \Gamma(\mathrm{B})=\Gamma^{*}(\mathrm{~B}) ; \Gamma(\mathrm{Ox})=K \mathrm{eq}[\Gamma(\mathrm{B})] \\
& \Gamma(\mathrm{Red})=0 \\
& t>0 ; \Gamma(\mathrm{B})+\Gamma(\mathrm{Ox})+\Gamma(\mathrm{Red})=\Gamma^{*}(\mathrm{~B}) \\
& {\left[\Gamma(\mathrm{Red})=\Gamma^{*}(\mathrm{~B})-\Gamma(\mathrm{B})-K \text { eq } \Gamma(\mathrm{B})\right]}
\end{aligned}
$$

At the working electrode, the Buttler-Volmer formalism has been applied, which links the current with the applied potential, the kinetics of electrode reactions and the surface concentrations of electroactive species $\Gamma(\mathrm{Ox})$ and $\Gamma(\mathrm{Red})$.

$$
(I / n F S)=k_{\mathrm{s}}{ }^{\circ} \exp (-\alpha \Phi)[\Gamma(\mathrm{Ox})-\exp (\Phi) \Gamma(\mathrm{Red})]
$$

It is worth to note that Marcus-Hush theory gives similar results as the Buttler-Volmer theory (in pulse voltammetric techniques) for redox reactions with moderate and fast electrode kinetics, as demonstrated in recent work of Compton et al. [29]. Numerical solution of equation (6) was obtained by using the method of Nicholson and Olmstead [64]. All parameters and the recurrent formulas for calculating the square-wave voltammograms of this mechanism are given in the Supplementary material of this work.

\section{Parameters Affecting the Features of Calculated Voltammograms}

The dimensionless current of calculated SW voltammograms is defined as $\Psi=I /\left[\left(n F S f \Gamma^{*}(\mathrm{~B})\right)\right]$. With $I$ we define the electric current, while $n$ is the number of electrons exchanged between working electrode and the electroactive species. In all calculations, we set $n=1$. $S$ is the active area of working electrode, while $f$ is the SW frequency defined as $f=1 /\left(2 t_{p}\right)$, where parameter $t_{p}$ is defined as time duration of a single potential pulse in SWV. " $\Gamma$ " is a symbol of the surface concentration. With $\Gamma^{*}(\mathrm{~B})$ we define the total surface concentration, which is, in fact, the initial surface concentration of adsorbed species B. $\Phi$ is a symbol of dimensionless potential defined as $\Phi=n F\left(E-E^{\circ} / R T\right)$, where $E^{\circ}$ is the standard redox potential of $\mathrm{Ox}_{(\mathrm{ads})} \leftrightarrow \operatorname{Red}_{(\mathrm{ads})}$ electrode reaction. $\alpha$ is a symbol of the electron transfer coefficient. We set $\alpha$ to value of 0.5 in all calculations. With $T$ we define the thermodynamic temperature (it was set to $298 \mathrm{~K}$ in all simulations), while $R$ is the universal gas constant, and $F$ is the Faraday constant. Calculated SW voltammograms 
are affected by several dimensionless parameters. The dimensionless electrode kinetic parameter $K=k_{\mathrm{s}}^{\circ} / f$ reflects the influence of standard rate constant of electron transfer $\left(k_{\mathrm{s}}^{\circ}\right)$ to the time duration of potential pulses in SWV. In addition, the features of calculated SW voltammograms are affected by the equilibrium constant of preceding chemical reaction $K \mathrm{eq}=\left(k_{\mathrm{f}} / k_{\mathrm{b}}\right)$, and by two dimensionless chemical parameters: $\varepsilon$ and $K_{\text {catalytic. }} \varepsilon$ is dimensionless chemical parameter related to the rate of preceding chemical step. It is defined as $\varepsilon=\left(k_{\mathrm{f}}+k_{\mathrm{b}}\right) / f$, where $k_{\mathrm{f}}$ and $k_{\mathrm{b}}$ are the first order rate constant of forward and backward steps of preceding chemical reaction, respectively. The dimensionless catalytic parameter $K_{\text {catalytic }}$ is related to the rate of regenerative (catalytic) reaction. It is defined as $K_{\text {catalytic }}=k_{\mathrm{c}}^{\prime} / f$, where $k_{\mathrm{c}}$ ' is the first order rate constant of the regenerative (catalytic) chemical reaction. At this stage, it is worth to emphasize that catalytic constant $k_{\mathrm{c}}$ ' is of pseudo-first order since it depends on concentration of substrate "Y": $k_{\mathrm{c}}{ }^{\prime}=k_{\mathrm{c}}{ }^{\circ} c(\mathrm{Y})$. In last equations, $k_{\mathrm{c}}{ }^{\circ}$ is a real chemical rate constant of regenerative reaction.

In all simulations, we used following parameters of applied potential: SW frequency $f=10 \mathrm{~Hz}, \mathrm{SW}$ amplitude $E_{\mathrm{sw}}=60 \mathrm{mV}$, and potential step $\mathrm{d} E=4 \mathrm{mV}$. More details of the algorithms used can be found in the Supplementary of this work. We used MATHCAD 14 software for calculating the SW voltammograms $[65,66]$. The net currents in all simulated voltammetric patterns are represented by black colour, while the forward (reduction) currents are assigned with blue colour. Red colour is associated with the backward (reoxidation) current branches at all simulated voltammograms. The starting potential is always set to positive values in all calculations.

\section{Results and Discussion}

At the beginning of this section, it is worth to emphasize several aspects important to this particular electrode mechanism. The initial amount of species (Ox) available for electrochemical transformation at the working electrode is governed by the value of equilibrium constant $K e q$ of preceding chemical step. However, the chemical equilibrium at the electrode surface gets disturbed during each applied potential pulse via the electrochemical reaction, but also via occurrence of preceding and regenerative chemical steps, too. While a fast preceding chemical reaction might influence the thermodynamics of the electrode reaction (by displacing the redox equilibrium), a fast regenerative chemical reaction may affect the rate of overall mechanism. Actually, the kinetics of preceding chemical reaction during each potential step is affected by the values of $\varepsilon$ and $K_{\text {catalytic }}$. When we discuss about terms "fast" and "slow", related to the rate of electrode transformation and the chemical reactions rates in voltammetry, we have to note that these terms are relative. This is because the time-scale at each applied SW potential pulse is important factor affecting all rates of chemical and electrochemical steps. As defined in pre- vious section, the dimensionless chemical rate parameters in this complex mechanism are affected both by the SW frequency, and by the concentration of substrate "Y" (via $K_{\text {catalytic }}$, for the catalytic chemical reaction). Since the SW frequency affects simultaneously all chemical and electron transfer parameters, we point out that all calculations in this work are performed at a constant SW frequency $f$. Therefore, we consider in our simulations mainly the effect of concentrations of "Y" to the features of SW voltammetric patterns. The SW voltammograms are calculated for various electrode kinetics, and different chemical rates $(\varepsilon)$ and equilibrium constants (Keq) of the preceding chemical reaction. Bearing in mind the mutual interplay of chemical steps in considered surface CEC' mechanism, we should expect SW voltammetric patterns that will be some sort of hybrids of surface CrevE, EC' and ECirr mechanisms.

Although this surface mechanism is quite complex, we can easily distinguish two limiting situations; A) if Keq > 10 , then the square-wave voltammograms show features of unperturbed "simple" surface mechanism and there is no influence of chemical parameter of preceding reaction $\varepsilon$ [31]. In such scenario, the simulated voltammograms of surface CEC' mechanism are identical to those of a surface EC' mechanism (Figure S1 in Supplementary material), whose features are elaborated in details elsewhere $[4,9,32]$; B) If catalytic parameter $K_{\text {catalytic }}<0.001$, then the calculated square-wave voltammograms have the same features as those of a surface CrevE mechanism as described in $[4,31]$. In this work we focus mainly on studying the effect of catalytic parameter $K_{\text {catalytic }}$ to the calculated SW voltammograms featuring moderate and fast rates of electrode reaction. In the theoretical calculations, we consider situations of moderate and small values of equilibrium constant $K$ eq, and small, moderate and large rates of preceding chemical reaction $\varepsilon$. When considering chemical complexes (metal-ligand, for example), the dissociation is the chemical step that supplies the starting electroactive species in $\mathrm{CE}$ mechanisms. In respect to the rate of electrode reaction, we consider in this work two cases: A) situation with moderate rate of electrode reaction: and $\mathrm{B}$ ) situation with fast rate of electrode reaction.

\subsection{Surface CEC' Mechanism Featuring Moderate Kinetics of Electrode Reaction}

Shown in Figures 1 and 2 (and also Figure S2 in Supplementary material) is a series of calculated SW voltammograms representing the effect of catalytic parameter $K_{\text {catalytic }}$ in case of electrode reaction featuring moderate kinetics of electron transfer $(K=0.1)$. The voltammograms are calculated for $K e q=0.1$, and for three values of chemical parameter of preceding reaction i.e. $\varepsilon=0.1$ (Figure 1), $\varepsilon=1$ (Figure S2) and $\varepsilon=100$ (Figure 2). For slow rates of preceding chemical reactions $(\varepsilon \leq$ 0.1 , Figure 1), an increase of catalytic parameter $K_{\text {catalytic }}$ leads to decrease of backwards and net SWV current 

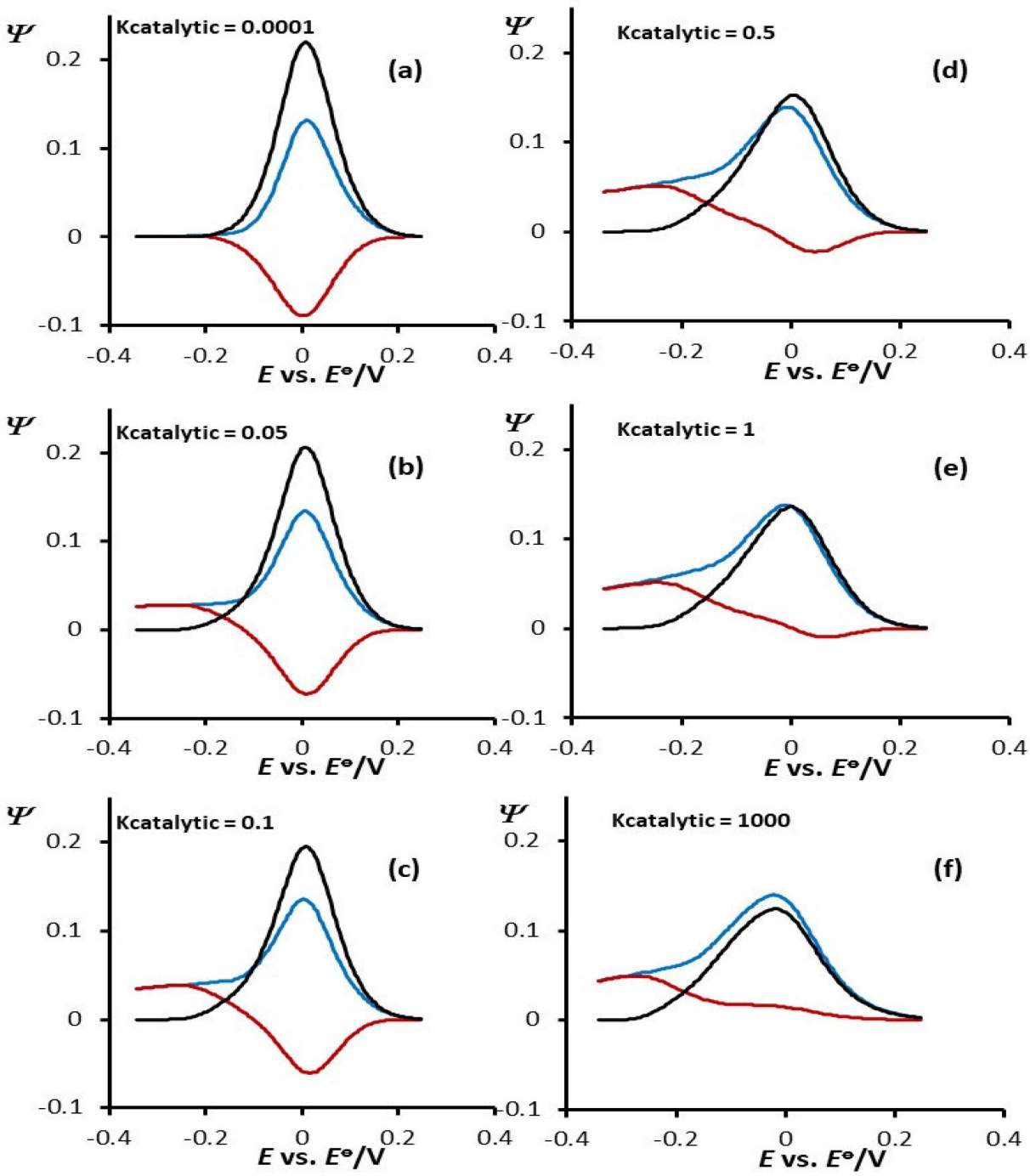

Fig. 1. Surface CEC' mechanism: sscenario with moderate value of equilibrium constant of preceding chemical reaction and small kinetics of preceding chemical reaction: Square-wave voltammograms of a surface CEC' mechanism showing the effect of rate of catalytic reaction to the features of calculated voltammetric patterns. The simulations are performed under following conditions: standard rate constant of electron transfer $\mathrm{k}_{\mathrm{s}}=10 \mathrm{~s}^{-1}$; SW frequency $\mathrm{f}=10 \mathrm{~Hz}$ (dimensionless electrode kinetic parameter $\mathrm{K}=1$ ); equilibrium constant of preceding chemical reaction $\mathrm{Keq}=0.1$, dimensionless rate parameter of preceding chemical reaction $\boldsymbol{\varepsilon}=\mathbf{0 . 1}$, electron transfer coefficient $\alpha=0.5$, number of electrons exchanged $\mathrm{n}=1$. Other potential modulation parameters were set to: potential increment $\mathrm{dE}=4 \mathrm{mV}$, and square-wave amplitude $\mathrm{E}_{\mathrm{sw}}=60 \mathrm{mV}$. The values of the dimensionless catalytic parameter $\mathrm{K}_{\text {catalytic }}$ are given in the charts.

components. For $K_{\text {catalytic }}>1$, there is no longer influence of catalytic parameter to calculated SWV patterns (see Figure 1e-f). The value of peak current of forward (reduction) SWV peak remains almost unchanged by increasing catalytic parameter $K_{\text {catalytic }}$ from 0.0001 to 1000. This is quite non-specific phenomenon for the surface catalytic EC' mechanisms [4,9,32]. It is important to point out that an increase of catalytic parameter in EC' mechanism is followed by a simultaneous decrease of the backward, and concomitant increase of the forward current branch (see Figure S1, for example) [9,32]. In scenario elaborated in Figure 2 and Figure S2, we observe influence of $K_{\text {catalytic }}$ to the backward (reoxidation) SW current component mainly. The forward (reduction) SWV current branch is affected only in the after-peak regions at more negative potentials, which gets slightly elevated by increasing of $K_{\text {catalytic }}$. The SWV patterns in Figure 2 and Figure S2 resemble much more to a surface ECirr mechanism $[4,35]$ rather than to a surface EC' regenerative mechanism. As the catalytic parameter contributes to regeneration of initial electroactive species $\mathrm{Ox}_{(\mathrm{ads})}$, expected voltammetric outputs should feature increase of the forward SW current branch by increasing of $K_{\text {catalytic }}$ as presented in Figure S1. The cause for the observed phenomena in Figure S2 is the chemical conversion of regenerated $\mathrm{Ox}(\mathrm{ads})$ to electrochemically inactive $\mathrm{B}_{(\mathrm{ads})}$ species during the current measuring time-frame at given potential SW pulses. As the rate of preceding chemical 

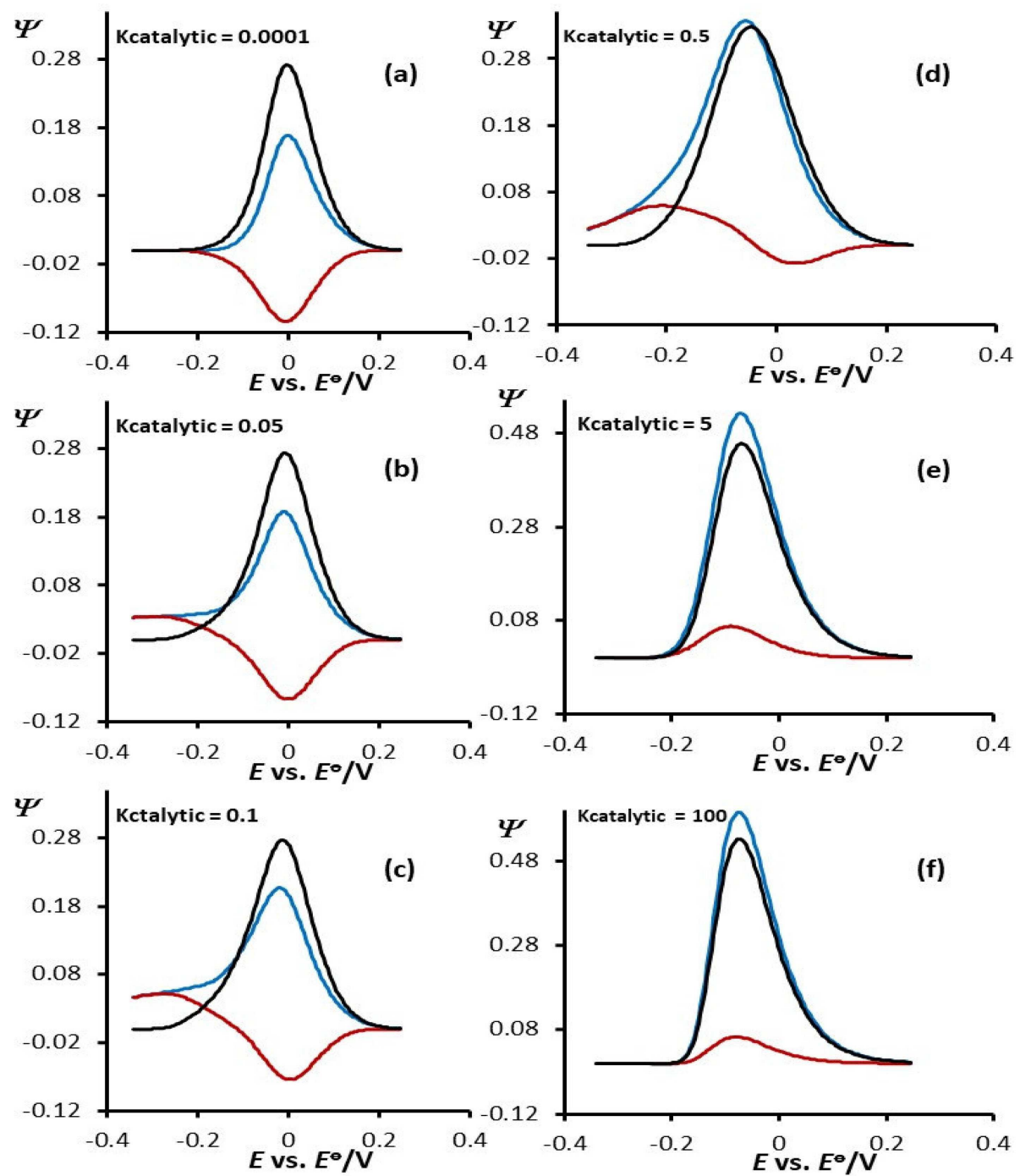

Fig. 2. Surface CEC' mechanism: scenario with moderate value of equilibrium constant of preceding chemical reaction and fast kinetics of preceding chemical reaction: Square-wave voltammograms of a surface CEC' mechanism showing the effect of rate of catalytic reaction to the features of calculated voltammetric patterns. Voltammograms are calculated for $\boldsymbol{\varepsilon}=\mathbf{1 0 0}$. The values of the dimensionless catalytic parameter $\mathrm{K}_{\text {catalytic }}$ are given in the charts. Other simulation parameters are same as in Figure 1.

step increases (Figures S2, and Figure 2), by increasing the rate of regenerative reaction we observe voltammetric patterns that resemble closely to those of a surface EC' mechanism in SWV. In such sequence of events, an increased rate of catalytic step is followed by increase of forward (and net) SWV current branches, and concomitant decrease of the backward SWV currents (Figure S2 a-e and Figure 2a-e). For $K_{\text {catalytic }}>1$, there is no further effect of catalytic rate on calculated voltammetric patterns and steady-state voltammograms are obtained, independent on $K_{\text {catalytic }}$ (Figure S2e-f and Figure 2e-f). Obviously, the obtained voltammetric patterns in such scenario (Figures S2 and Figure 2) are sort of "hybrid-like" voltammograms of a surface CE and surface EC' mechanisms. This is because the complex interplay of the two chemical rate parameters $\varepsilon$ and $K_{\text {catalytic, }}$, whose absolute values determine the shape of voltammetric patterns.
Shown in Figure 3 are the dependences between the net SWV peak currents- $\Psi_{\text {net,p }}$ and the peak-potentials- $E_{\text {net, }}$, p of net SWV peaks as a function of $\log \left(K_{\text {catalytic }}\right)$, calculated for several values of chemical parameter $\varepsilon$. The dependences in Figure 3 are quite unusual, since the trends depend on the value of chemical parameter $\varepsilon$. For $\varepsilon>1$, the shape of the curves of $\Psi_{\text {net,p }}$ and $E_{\text {net,p }}$ as a function of $\log \left(K_{\text {catalytic }}\right)$ resemble to those of a surface CE reaction [31,71], while for $\varepsilon<1$, they resemble to the shape of curves typical of surface ECirr reaction $[4,35]$. The dependences at Figure 3 portray the complex interplay between the equilibrium constant and the both chemical parameters. A quite unusual phenomenon at Figure 3 is observed for high values of $\varepsilon$. By increasing the value of chemical parameter $\varepsilon($ for $K$ eq $<1)$, an increase of the catalytic parameter leads to increase of the net peak current (yellow and blue circles in Figure 3A). 

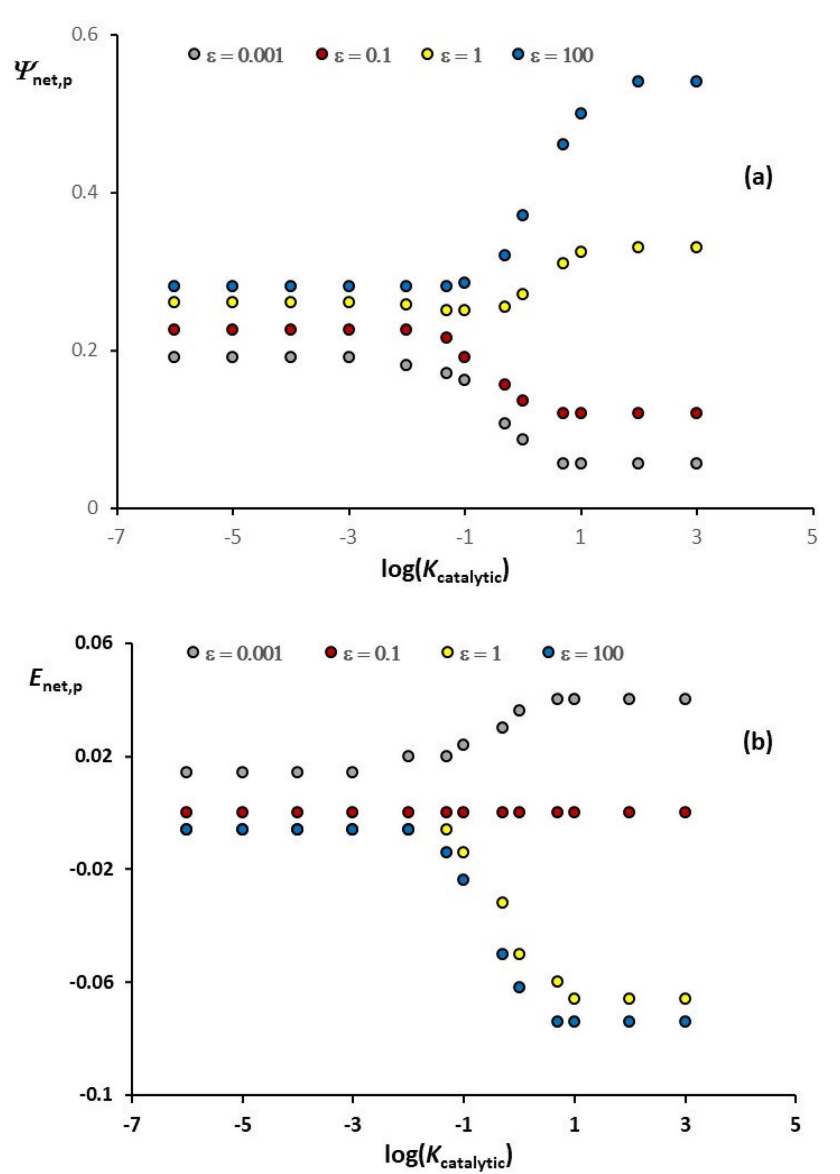

Fig. 3. Dependences between the net SWV peak currents- $\Psi_{\text {net,p }}$ (a) and the peak-potentials- $E_{\text {net,p }}$ (b) of net SWV peaks as a function of $\log \left(K_{\text {catalytic }}\right)$. The curves are calculated for several values of chemical parameter $\varepsilon$ that are given in the charts. The value of electrode kinetic parameter was $K=1(f=10 \mathrm{~Hz})$, while the value of equilibrium constant of preceding chemical reaction was $K$ eq $=0.1$. Other simulation parameters are same as in Figure 1.

Indeed, this effect is opposite of that observed by the surface CE mechanism [31]. This phenomenon appears due to the mutual interplay of both chemical parameters $\varepsilon$ and $K_{\text {catalytic }}$ that disturb significantly all equilibriums in considered mechanism (I) during the current measuring time-window. Moreover, we should also remember that all steps of surface CEC' mechanism (i.e. the chemical, electrochemical, and regenerative step) take place also in the so-called "dead-time" (or non-current measuring time window) of each potential pulse [35]. As shown in our recent works [35,66], the chemical and electrochemical reactions going on in the "dead-time" of many potential pulses may lead to phenomena that are opposite than those "expected" by EC or CE reactions. Indeed, the specific current measuring manner in SWV also contributes significantly to the phenomena observed at this complex surface electrode mechanism.

The catalytic parameter $K_{\text {catalytic }}$ produces similar voltammetric patterns as those presented in Figure 1, when $K$ eq $\leq 0.001$, for values of chemical parameter $\varepsilon<1$ (not shown). However, for $K$ eq $\leq 0.001$, and for large values of chemical parameter $\varepsilon$, we observe very interesting voltammetric patterns produced by $K_{\text {catalytic }}$. Shown in Figure 4 is a series of calculated voltammograms representing the effect of catalytic parameter $K_{\text {catalytic }}$, simulated for $K=0.1, K$ eq $=0.0001$ and $\varepsilon=100$. An increase of catalytic parameter $K_{\text {catalytic }}$ up to 0.5 produces slight initial increase of the forward and decrease of the backward SW current components, which is followed by increase of the net SWV peak currents (Figure 4b-f). For $K_{\text {catalytic }}>1$, we observe voltammetric patterns typical to a surface EC' mechanism characterized with large kinetics of catalytic reaction (Figure $4 \mathrm{~g}-\mathrm{j}$ ) $[9,32]$. For large rates of regenerative reaction $\left(K_{\text {catalytic }}>0.5\right)$, the peak-currents of net SWV peak increase linearly in proportion with $K_{\text {catalytic. }}$ In such scenario, another remarkable phenomenon is a shift of the net SWV peak-potentials towards more negative values. This is a specific feature of a surface EC' mechanism that is explained in more details in [32]. Shown in Figure 5 are the dependences between net SWV peak currents- $\Psi_{\text {net,p }}(\mathrm{A})$ and the peak-potentials- $E_{\text {net,p }}(\mathrm{B})$ of net SWV peaks as a function of $\log \left(K_{\text {catalytic }}\right)$. Curves on Figure 5 are simulated for several values of chemical parameter $\varepsilon$, and for $K e q=0.0001$. The only obvious difference in the shape of the curves given at Figure 5, compared with corresponding curves at Figure 3 , is seen at high values of chemical parameter $\varepsilon=100$ (curves with yellow circles at Figure 5). For large rates of chemical preceding reaction, the features of $\Psi_{\text {net,p }}$ and $E_{\text {net,p }}$ as a function of $\log \left(K_{\text {catalytic }}\right)$ resemble to those of a surface EC' mechanism, when $K_{\text {catalytic }}>0.5$ [32]. Obviously, high rates of preceding chemical reaction contribute to quick re-establishment of equilibrium of electroactive species at working electrode surface, turning quickly the surface CEC' mechanism into a "simple" surface EC' mechanism. In such scenario, one can use the methodologies elaborated in [32] to evaluate the standard rate constant of electron transfer, and the rate constant of catalytic reaction as well. This can be achieved by altering the concentration of regenerative agent "Y" only, and by using the dependences of $\Psi_{\text {net,p }}$ and $E_{\text {net,p }}$ as a function of substrate molar concentration $c(\mathrm{Y})$ given in [32].

\subsection{Surface CEC' Mechanism Featuring Fast Kinetics of Electron Transfer Step}

One of the most recognizable characteristics of surface reactions in square-wave voltammetry is the "splitting of net SWV peak" [4,37]. As described in [37], the phenomenon of "net-peak splitting in SWV" is attributed to surface-confined electrode processes featuring fast electron exchange between working electrode and the redox adsorbates. When electron transfer rate is large, then the time needed for transformation of $\mathrm{Ox}\left(_{(\mathrm{ads})}\right.$ to $\operatorname{Red}_{(\mathrm{ads})}$ at given potential of defined SWV pulses becomes very short. Consequently, when the duration of given SW pulse is longer than the time needed to achieve electrochemical 

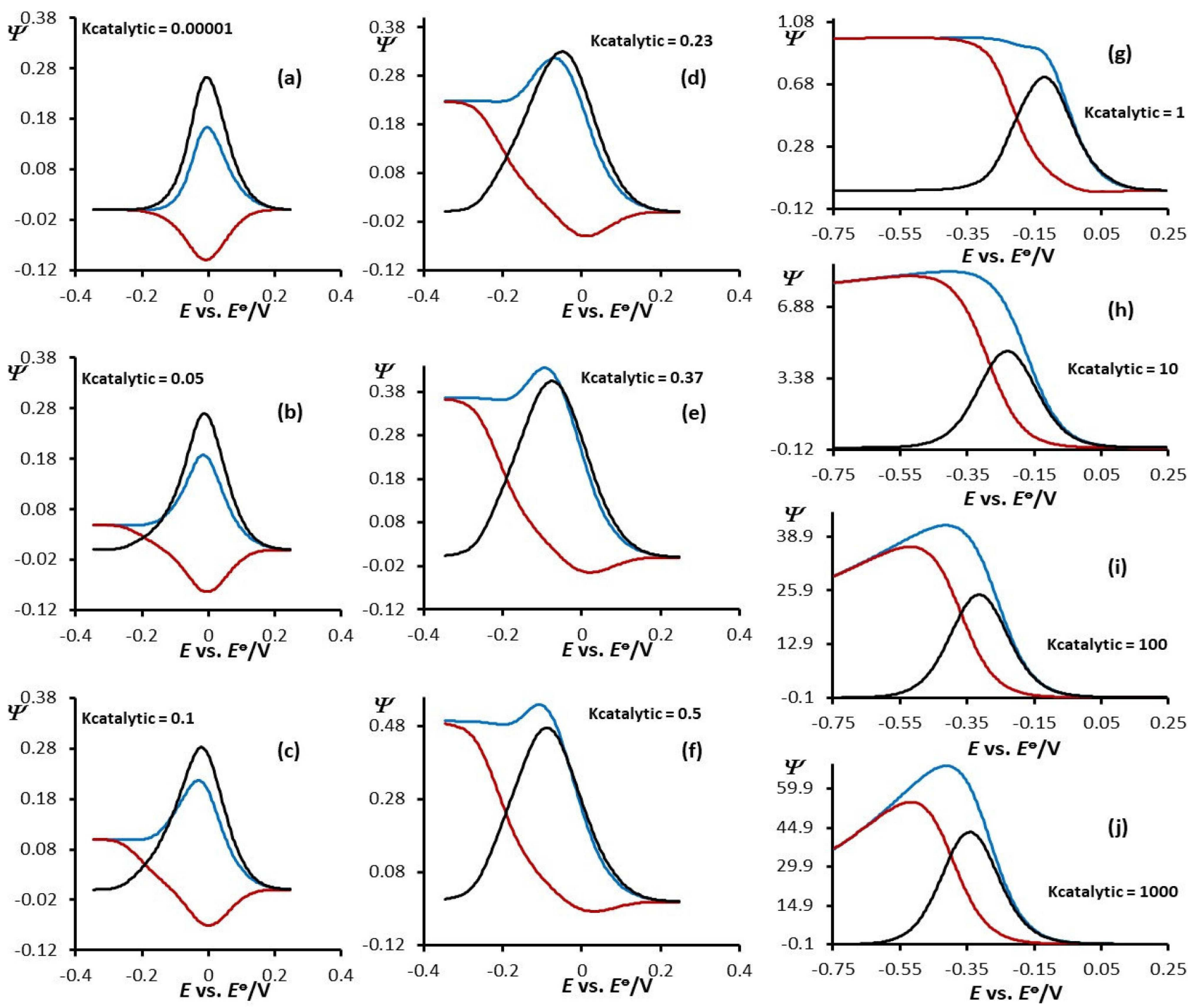

Fig. 4. Surface CEC' mechanism: scenario with small value of equilibrium constant of preceding chemical reaction and fast kinetics of preceding chemical reaction: Square-wave voltammograms of a surface CEC' mechanism showing the effect of rate of catalytic reaction to the features of calculated voltammetric patterns. Voltammograms are calculated for Keq $=\mathbf{0 . 0 0 0 1}$ and $\boldsymbol{\varepsilon}=\mathbf{1 0 0}$. The values of the dimensionless catalytic parameter $\mathrm{K}_{\text {catalytic }}$ are given in the charts. Other simulation parameters are same as in Figure 1.

transformation of $\mathrm{Ox}_{(\mathrm{ads})}$ to $\operatorname{Red}_{(\mathrm{ads})}$, the currents that will be measured at the end of defined SW pulses would be very small. This will produce a small (in terms of measured currents) overall voltammetric response. Moreover, under such circumstances, both oxidation and reduction electrode steps require lower energy to occur. As the kinetics of electron transfer step increases, both reduction and oxidation peaks will start to shift towards potentials that are equivalent of lower energy. The final output of these events will be "splitting of the net SWV peak" [37]. As demonstrated in several works $[4,7,10,11,71]$, the phenomenon of splitting of net SWV peak can be successfully applied for estimation of kinetics of electrode reaction in a very simple manner. In this work, we focus on electrode reactions featuring fast electron transfer, and small value of equilibrium constant of preceding chemical reaction. We evaluate the role of the rate of regenerative chemical reaction to calculated SW voltammograms, in situations of slow, moderate and large rates of preceding chemical reaction. Shown in Figure 6 is the effect of rate of regenerative reaction to the SW voltammograms of surface CEC' mechanism. Voltammograms are simulated for small equilibrium constant of preceding chemical reaction $(K e q=0.001)$ and very small kinetic of preceding chemical step $(\varepsilon=0.001)$. Interestingly, the SW voltammograms, simulated under such conditions, resemble to the voltammetric patterns typical of a surface EC mechanism $[4,35,36,66]$. An increase of $K_{\text {catalytic }}$ up to value of 0.25 produces decrease of the backward (reoxidation) SW current component and slight increase of the forward SWV current branch (Figure $6 \mathrm{a}-\mathrm{c})$. For $K_{\text {catalytic }}>0.5$ the splitting phenomenon vanishes and a single irreversible-like SW pattern is observed (Figure 6d). Any further increase of rate of 

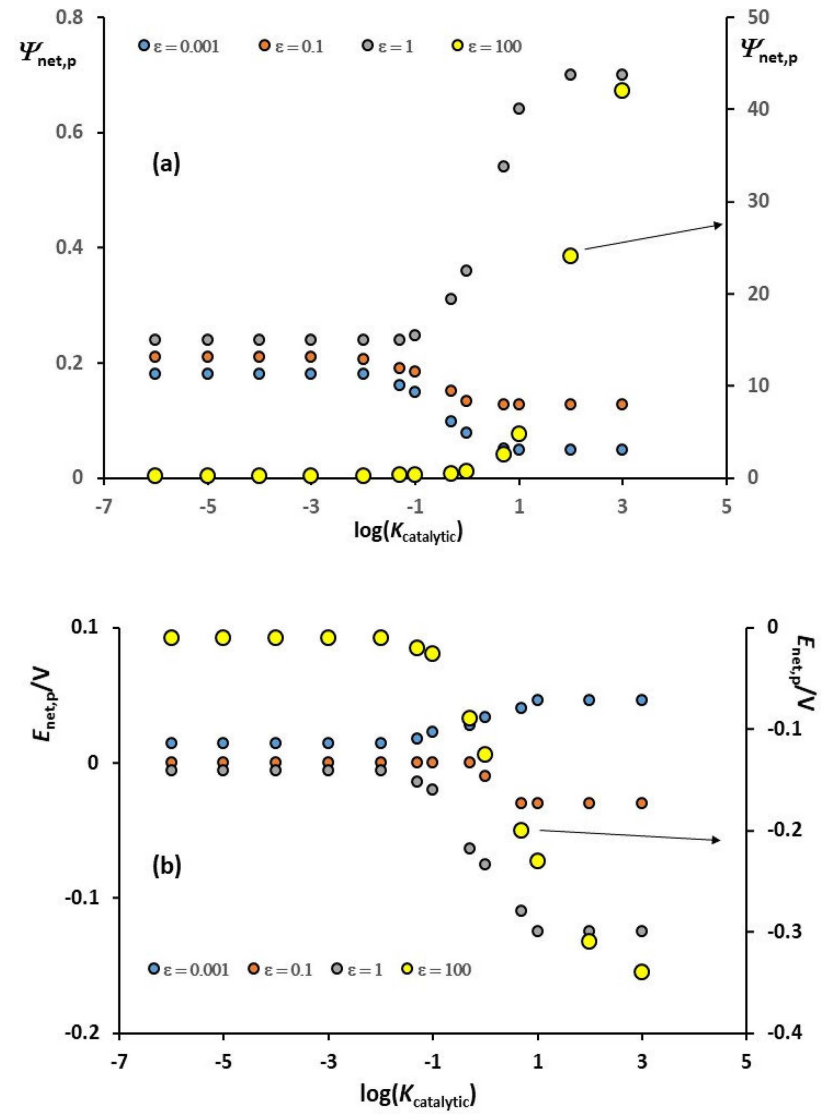

Fig. 5. Dependences between the net SWV peak currents- $\Psi_{\text {net,p }}$ (a) and the peak-potentials- $E_{\text {net,p }}$ (b) of net SWV peaks as a function of $\log \left(K_{\text {catalytic }}\right)$. The curves are calculated for very small value of equilibrium constant of preceding chemical reaction $K e q=0.0001$, and for several values of chemical parameter $\varepsilon$ that are given in the charts. The value of dimensionless electrode kinetic parameter was $K=1(f=10 \mathrm{~Hz})$. Other simulation parameters are same as in Figure 1.

regenerative step from $K_{\text {catalytic }}=1$ to $K_{\text {catalytic }}=100$, produces no effect to the net peak currents of SW voltammograms. However, it does influence the peak-potential of net SWV peak (Figure $6 \mathrm{~d}-\mathrm{f}$ ). In this region of rates of catalytic reaction, a linear dependence exists between the SWV net-peak potentials $E_{\text {net,p }}$ and $\log \left(K_{\text {catalytic }}\right)$, with slope of $40 \mathrm{mV} / \log \left(K_{\text {catalytic }}\right)$. For $K_{\text {catalytic }}>100$, a steadystate SW voltammograms are obtained, independent on $K_{\text {catalytic. }}$.

Different SWV patterns than those in Figure 6 are obtained under influence of regenerative reaction rates, calculated for $\varepsilon=0.1$.

Under such conditions, up to $K_{\text {catalytic }}=1$, we observe SWV patterns as expected of a surface catalytic EC' mechanism [4,9,32] (Figure 7a-d). However, a further increase of $K_{\text {catalytic }}$ produces no effects to the currents of simulated SW voltammograms (Figure 7e-f). Important to stress in such scenario is the existence of elevated currents in the after-peak region. This feature is typical for regenerative EC' mechanism, produced at large rates of regenerative reaction (see Figure S1) $[9,32]$. In the
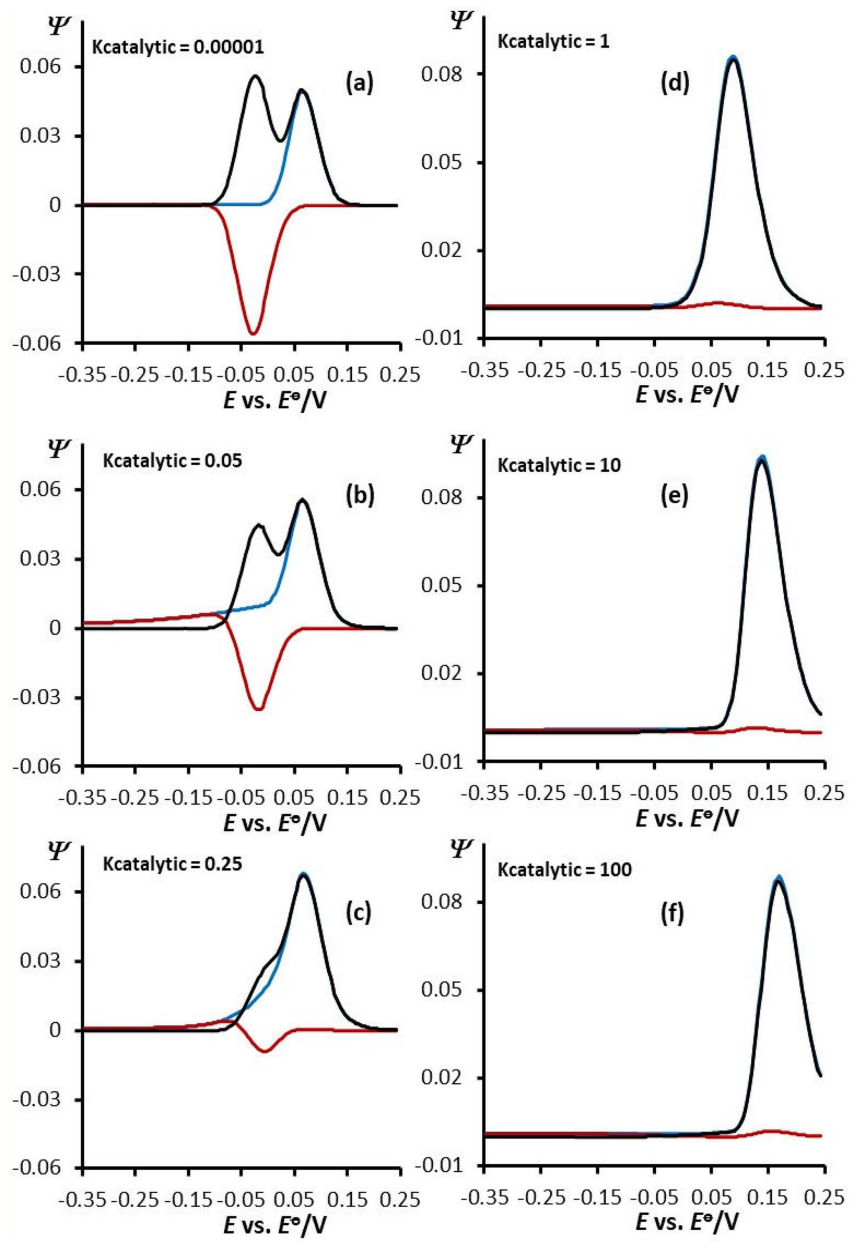

Fig. 6. Surface CEC' mechanism: scenario with small value of equilibrium constant of preceding chemical reaction and very small kinetics of preceding chemical reaction: Square-wave voltammograms of a surface CEC' mechanism showing the effect of rate of catalytic reaction to the features of calculated voltammetric patterns. Voltammograms are calculated for Keq $=$ $\mathbf{0 . 0 0 0 1}$ and $\boldsymbol{\varepsilon}=\mathbf{0 . 0 0 1}$. The value of the dimensionless electrode kinetic parameter was $\mathrm{K}=3.162\left(\mathrm{k}_{\mathrm{s}}=31.62 \mathrm{~s}^{-1} ; \mathrm{f}=10 \mathrm{~Hz}\right)$. The values of the dimensionless catalytic parameter $\mathrm{K}_{\text {catalytic }}$ are given in the charts. Other simulation parameters are same as in Figure 1.

region of $1<K_{\text {catalytic }}<100$, a linear dependence exists between the SWV net-peak potentials $E_{\text {net,p }}$ and log $\left(K_{\text {catalytic }}\right)$, with slope of $40 \mathrm{mV} / \log \left(K_{\text {catalytic }}\right)$, identically as in Figure 6. It is worth to mention that the shift of net SWV peak-potentials to more positive values (for reaction $\mathrm{Ox}_{(\mathrm{ads})}+$ ne $\left.-\leftrightarrow \operatorname{Red}_{(\mathrm{ads})}\right)$ under the influence of chemical rate parameter is a feature typical for EC mechanism [4,35,36], but not for EC' [32] or CE systems [31]. Again, for $K_{\text {catalytic }}>100$, a steady-state SW voltammograms are obtained, independent on regenerative reaction rates.

Shown in Figure 8 is the effect of rate of catalytic parameter $K_{\text {catalytic }}$ to the SW voltammograms calculated for $K e q=0.001$, and for significant rates of preceding chemical reaction $(\varepsilon=1000)$. Under such circumstances, we observe voltammetric patterns that are sort of 

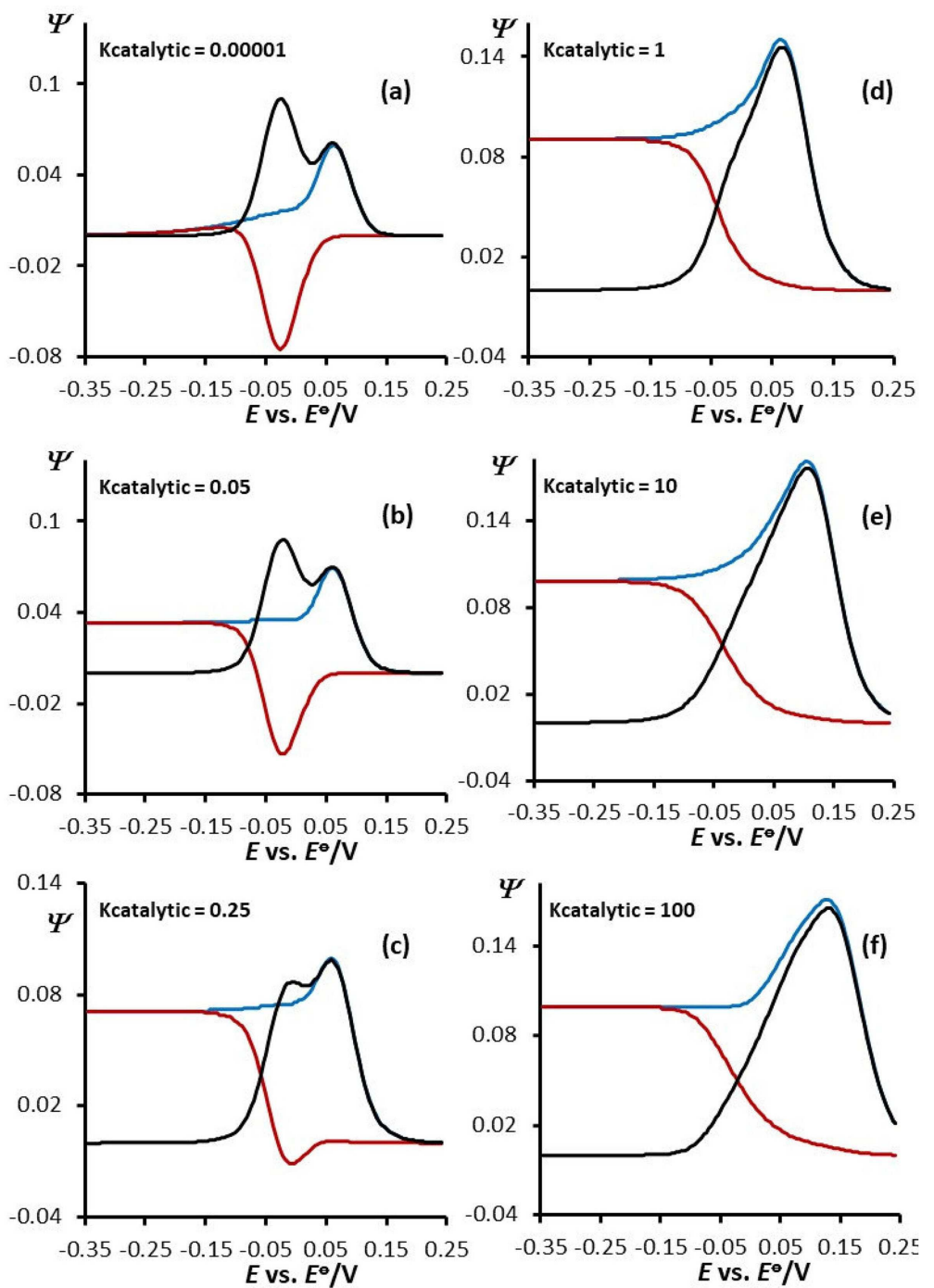

Fig. 7. Surface CEC mechanism: scenario with small value of equilibrium constant of preceding chemical reaction and small kinetics of preceding chemical reaction: Square-wave voltammograms of a surface CEC' mechanism showing the effect of rate of catalytic reaction to the features of calculated voltammetric patterns. Voltammograms are calculated for $\mathbf{K e q}=\mathbf{0 . 0 0 0 1}$ and $\boldsymbol{\varepsilon}=\mathbf{0 . 1}$. The value of the dimensionless electrode kinetic parameter was $\mathrm{K}=3.162$. The values of the dimensionless catalytic parameter $\mathrm{K}_{\text {catalytic }}$ are given in the charts. Other simulation parameters are same as in Figure 1.

"hybrids" SW voltammograms of surface CE, EC and EC' mechanisms. As the dimensionless catalytic parameter increases up to $K_{\text {catalytic }}=100$, we observe SWV features recognizable for surface EC' mechanism of fast electrode reactions (Figure 8a-e). However, for $K_{\text {catalytic }}>$ 10 (Figure 8f), the forward and backward current branches start to lose their sigmoidal shape typical of EC' mechanism $[9,32]$. Under influence of high catalytic rates, the forward (reduction) and backward (reoxidation) current branches start to get shape as that of a surface EC mechanism [35,36]. In the same direction, the peak potentials of net SWV peaks shift for $-30 \mathrm{mv} / \log \left(K_{\text {catalytic }}\right)$ in the region $1<K_{\text {catalytic }}<1000$, which is typical for surface EC' mechanism [32]. For $K_{\text {catalytic }}>1000$, there is no longer effect of regenerative reaction to the shape of calculated voltammetric patterns and steady-state SW voltammo- grams are obtained, independent on $K_{\text {catalytic }}$ Indeed, the obtained patterns in Figure 8 are due to the competitive large kinetics between the regenerative and the preceding chemical reaction. The voltammetric patterns presented in Figure 8 can serve as a diagnostic criterion to recognize the surface CEC' mechanism featuring fast electrode step and fast rates of preceding chemical reaction.

In the end of this section, it is worth to mention that the phenomenon of "quasireversible maximum" is very useful methodology to get access to the kinetics of electron transfer reaction between working electrode and the redox adsorbates as explained in $[4,67]$. In the elaborated surface CEC' mechanism, the position of "quasireversible maximum" is affected neither by chemical parameters $\varepsilon$ [32] nor by catalytic parameter $K_{\text {catalytic }}$ (see Figure 9). Consequently, this phenomenon can be 

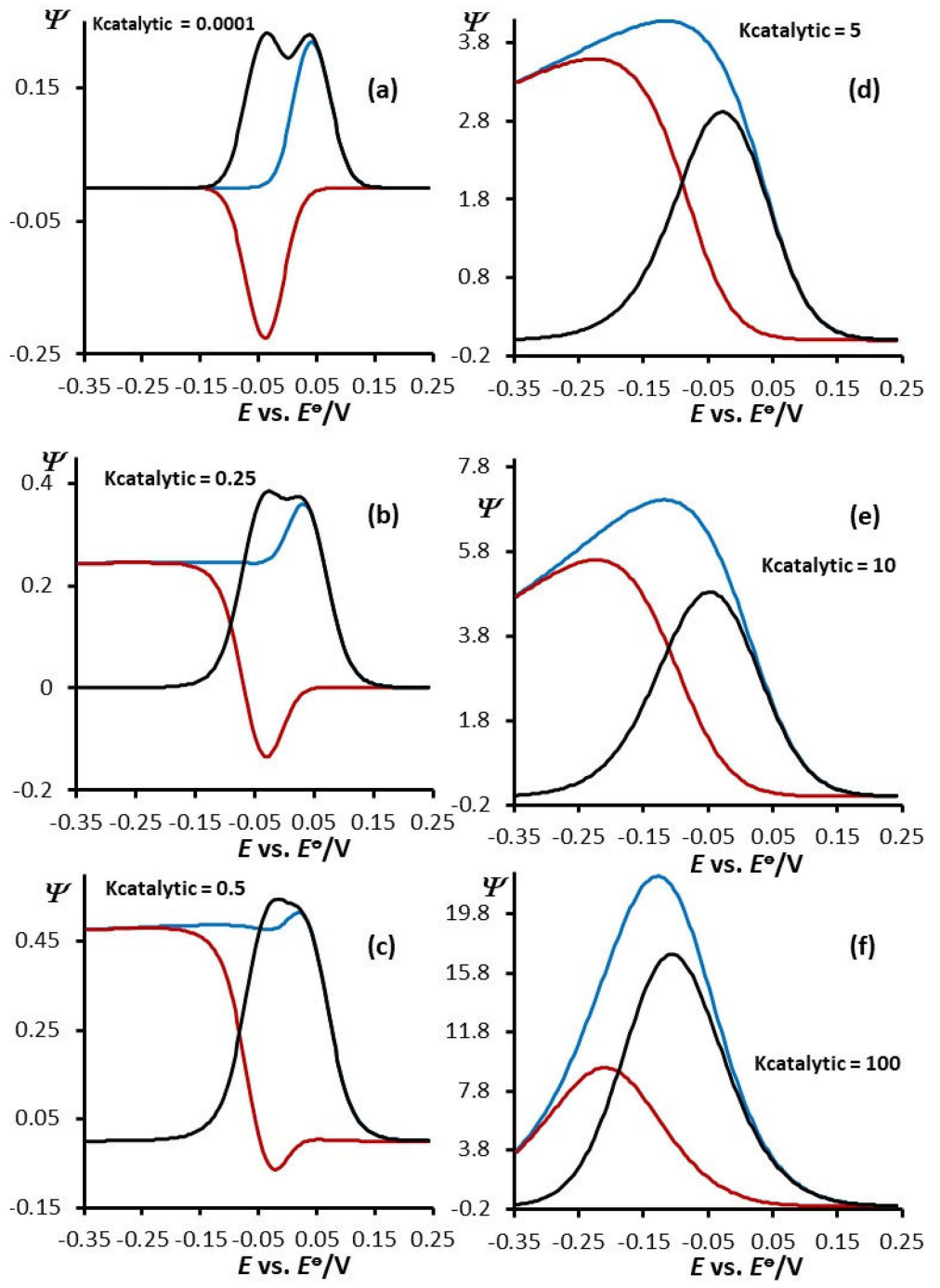

Fig. 8. Surface CEC' mechanism: scenario with small value of equilibrium constant of preceding chemical reaction and large kinetics of preceding chemical reaction: Square-wave voltammograms of a surface CEC' mechanism showing the effect of rate of catalytic reaction to the features of calculated voltammetric patterns. Voltammograms are calculated for Keq $=\mathbf{0 . 0 0 0 1}$ and $\boldsymbol{\varepsilon}=\mathbf{1 0 0 0}$. The value of the dimensionless electrode kinetic parameter was $\mathrm{K}=3.162$. The values of the dimensionless catalytic parameter $\mathrm{K}_{\text {catalytic }}$ are given in the charts. Other simulation parameters are same as in Figure 1.

explored for the determination of standard rate constant of electron transfer $k_{\mathrm{s}}^{\circ}$, regardless of the values of $\varepsilon$ and $K_{\text {catalytic }}$. For the determination of $K$ eq and $\varepsilon$ parameters, one can use the methodologies elaborated in our work [31], in experiments performed in absence of catalytic agent "Y".

It is also worth to emphasize that we do not consider in details the effect of electron transfer coefficient, since it will bring more complexity to this work. To get insight into the effects of electron transfer coefficients to the SW voltammetric outputs of surface electrode mechanism, the readers are advised to references $[4,13]$.

\section{Conclusions}

Surface-confined electrochemical reactions, which are complicated with chemical steps, attract significant inter- est in many voltammetric studies. This is because voltammetry of surface redox reactions is a cheap, simple and fast technique to study the chemical reactivity of many lipophilic compounds ranging from enzymes, drugs and other important physiologically relevant substances. In this work we report on theoretical results of a surface CEC' mechanism for the very first time under conditions of square-wave voltammetry. From the calculated voltammetric patterns, we got a quite complex picture of this mechanism that is a consequence of the mutual interplay of two different kinetic chemical parameters with the kinetics of electrode step. The situation is additionally complicated by the specific measuring manner of the current in SWV [4-6,35]. The surface CEC' mechanism can be rationalized to a surface EC' mechanism (if equilibrium constant of preceding chemical reaction is large, i.e. $K e q>10$ ), or to a surface CE mechanism (if 


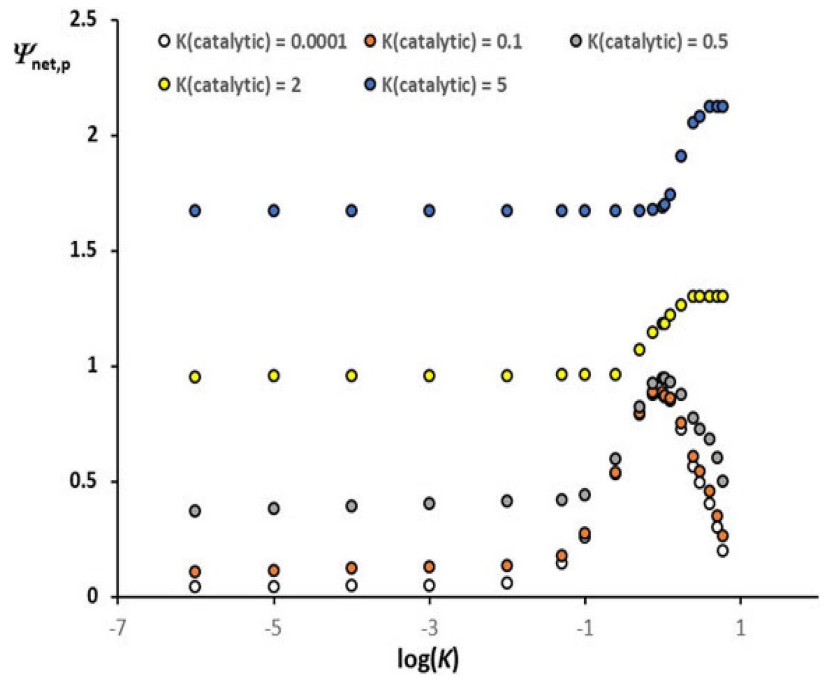

Fig. 9. "Quasireversible maxima" of surface CEC' mechanism calculated for several values of catalytic parameter $K_{\text {catalytic }}$. The curves are simulated for $K$ eq $=0.001$ and $\varepsilon=10$. The values of the dimensionless catalytic parameter $K_{\text {catalytic }}$ are given in the chart. Other parameters are same as in Figure 1.

catalytic parameter of regenerative reaction is small i.e. $\left.K_{\text {catalytic }}<0.001\right)$. In all other scenarios, we obtain rather complex SW voltammograms that are "hybrids" of the voltammetric patterns as typical of surface $\mathrm{CE}, \mathrm{EC}$ ' or EC reactions. The calculated voltammetric patterns at small values of the equilibrium constant of preceding chemical reaction are quite relevant in studying the electrochemistry of many metal-ligand (or other) complexes. Indeed, the metal-ligand complexes, via dissociation step, can produce electroactive material that serves as initial redox adsorbate in electrochemical step of a given surface CE mechanism [31]. As we have shown in this work, initial task in elaborating surface electrode processes coupled with two chemical reactions, is to recognize the nature of mechanism going on. The next step is the evaluation of relevant kinetic and thermodynamic parameters affecting the voltammetric patterns. Evaluating kinetic parameters from frequency-dependent experiments in SWV is not an easy task. This is because all kinetic parameters of the surface CEC' mechanism in SW voltammetry are affected simultaneously by the SW frequency. Therefore, variation of the SW frequency will produce complex voltammetric patterns due to the mutual interplay between all chemical and electrode kinetic parameters in this particular mechanism. In order to avoid such complexity in real experiments, one should perform experiments at constant SW frequency, but also at constant scan increment and constant SW amplitude. This is because both, the scan increment $\mathrm{d} E$ and the square-wave amplitude $E_{\mathrm{sw}}$ also affect the kinetics of electrode reaction [4]. The reported voltammetric patterns in this work can be experimentally reproduced by performing experiments at constant frequency, $\mathrm{d} E$ and $E_{\mathrm{sw}}$, and by varying the concentration of regenerative chemical compound " $Y$ " only.

\section{Acknowledgements}

Rubin Gulaboski thanks "Goce Delcev" University in Stip, Macedonia, for the support of this work via scientific project funded by the University. All authors thank prof. Valentin Mirceski (Macedonia) and prof. Milivoj Lovric (Croatia) for their useful discussions.

\section{References}

[1] A. Molina, J. Gonzales, Pulse voltammetry in physical electrochemistry and electroanalysis, in Monographs in electrochemistry (F. Scholz, ed.), Berlin Heidelber, Springer, 2016.

[2] R. G Compton, C E. Banks, Understanding voltammetry, 2

[3] A. J. Bard, L. R. Faulkner, Electrochemical methods. Fundamentals and applications, $3^{\text {rd }}$ edition, John Wiley \& Sons, Inc. 2004.

[4] V. Mirceski, S. Komorsky-Lovric, M. Lovric, Square-wave voltammetry, Theory and application, Springer, Berlin, Germany, 2007.

[5] M. Lovric, "Square-wave voltammetry," in Electroanalytical Methods, F. Scholz, Ed. Springer, Berlin, Germany, $2^{\text {nd }}$ edition, 2010.

[6] J. G. Osteryoung, J. J. O'Dea, Square-Wave Voltammetry, Electroanalytical chemistry: a series of advances. Marcel Dekker, Inc: New York, 1986.

[7] R. Gulaboski, V. Mirceski, I. Bogeski, M. Hoth, J. Solid State Electrochem. 2012, 16, 2315.

[8] R. Gulaboski, P. Kokoskarova, S. Mitrev, Electrochim. Acta 2012, 69, 86.

[9] V. Mirceski, R. Gulaboski, Electroanalysis 2001, 13, 1326.

[10] V. Mirceski, R. Gulaboski, Maced. J. Chem. Chem. Eng. 2014, 33, 1 .

[11] V. Mirceski, R. Gulaboski, M. Lovric, I. Bogeski, R. Kappl, M. Hoth, Electroanalysis 2013, 25, 2411.

[12] R. Gulaboski, M. Lovric, V. Mirceski, I. Bogeski, M. Hoth, Biophys. Chem. 2008, 137, 49.

[13] R. Gulaboski, M. Lovric, V. Mirceski, I. Bogeski, M. Hoth, Biophys. Chem. 2008, 138, 130.

[14] E. Laborda. J. Gonzales, A. Molina, Electrochem. Commun. 2014, 43, 25.

[15] A. Molina, J. Gonzales, M. Henstridge, R. G. Compton, Electrochim. Acta 2011, 56, 4589.

[16] A. Molina, R. G. Compton, C. Serna, F. Martinez-Ortiz, E. Laborda, Electrochim. Acta 2009, 54, 2320.

[17] M. Lovric, J. Osteryoung, Electrochim. Acta 1982, 27, 963.

[18] M. Lovric, J. J. O'Dea, J. Osteryoung, Anal. Chem. 1983, 55, 704.

[19] C. Serna, A. Molina, J. Electroanal. Chem. 1999, 466, 8.

[20] A. Molina, F. Martinez-Ortiz, E. Laborda, R. G. Compton, Electrochim. Acta 2010, 55, 5163.

[21] F. Garay, C. A. Barbero, Anal. Chem. 2006, 78, 6740.

[22] A. Molina, F. Martinez-Ortiz, E. Laborda, R. G. Compton, J. Electroanal. Chem. 2010, 648, 67.

[23] M. Lovric, Electroanalysis 1999, 11, 1089.

[24] A. Molina, C. Serna. L. Camacho, J. Electroanal. Chem. 1995, 394, 1.

[25] R. Gulaboski, J. Solid State Electrochem. 2009, 13, 1015.

[26] R. Gulaboski, L. Mihajlov, Biophys. Chem. 2011, 155, 1.

[27] P. Kokoskarova, V. Maksimova, M. Janeva, R. Gulaboski Electroanalysis 2019, 31, 1454. 
[28] R. Gulaboski, P. Kokoskarova, S. Petkovska, Croat. Chem. Acta 2018, 91, 377.

[29] E. Laborda, M. Henstridge, A. Molina F. Martinez-Ortiz, R. G. Compton, J. Electroanal. Chem. 2011, 660, 169.

[30] F. Garay, M. Lovric, J. Electroanal. Chem. 2002, 518, 91.

[31] R. Gulaboski, V. Mirceski, M. Lovric, I. Bogeski, Electrochem. Commun. 2005, 7, 515.

[32] R. Gulaboski, V. Mirceski, Electrochim. Acta 2015, 167, 219.

[33] V. Mirceski, D. Guzijewski, K. Lisichkov, Electrochim. Acta 2013, 114, 667 .

[34] D. Guziejewski, V. Mirceski, D. Jadresko, Electroanalysis 2015, 27, 67.

[35] R. Gulaboski, Electroanalysis 2019, 31, 545.

[36] R. Gulaboski, M. Janeva, V. Maksimova, Electroanalysis 2019, 31, 946.

[37] V. Mirceski, M. Lovric, Electroanalysis 1997, 9, 1283.

[38] M. Lovric, J. Electroanal. Chem. 1983, 153, 1.

[39] R. Meunier-Prest, E. Laviron, J. Electroanal. Chem. 1996, 410, 133.

[40] A. B. Miler, R. G. Compton, J. Phys. Chem. B 2000, 104, 5331.

[41] J. J. O'Dea, J. G. Osteryoung, Anal. Chem. 1997, 69, 650.

[42] A. Molina, C. Serna, M. López-Tenés, M. M. Moreno, J. Electroanal. Chem. 2005, 576, 9.

[43] J. Galvez, R. Saura, A. Molina, T. Fuente, J. Electroanal. Chem. 1982, 139, 15.

[44] J. Osteryoung, J. J. O'Dea, Square-wave voltammetry, in Electroanalytical Chemistry, A. J. Bard, Ed. Marcel Dekker, New York, NY, USA, 1986, 14, 209.

[45] E. Laborda, J. Gonzales, A. Molina, Electrochim. Acta 2014, 43, 25.

[46] J. J. O’Dea, J. G. Osteryoung, Anal. Chem. 1993, 65, 3090.

[47] J. J. O'Dea, J. Osteryoung, R. A. Osteryoung, Anal. Chem. 1981, 53, 695.

[48] M. Lovric, D. Jadresko, Electrochim. Acta 2010, 55, 948.

[49] V. Mirceski, M. Lovric, R. Gulaboski, J. Electroanal. Chem. 2001, $515,91$.

[50] J. Galvez, M. L. Alcaraz, S. M. Park, J. Electroanal. Chem. 1989, 266, 1.

[51] M. Lovric, S. Komorsky-Lovric, Intern. J. Electrochem. 2012, https://doi.org/10.1155/2012/596268.
[52] S. Komorsky-Lovric, M. Lovric, J. Electroanal. Chem. 2011, 660, 22.

[53] P. Song, A. C. Fisher, J. D. Wadhawan, J. J. Cooper, H. J. Ward, N. S. Lawrence, RSC Adv. 2016, 6, 70237.

[54] V. Mirceski, E. Laborda, D. Guziejewski, R. Compton, Anal. Chem. 2013, 85, 5586.

[55] V. Mirceski, D. Guzijewski, M. Bozem, I. Bogeski, Electrochim. Acta 2016, 213, 520.

[56] C. Batchelor-McAuley, E. Katelhon, E. O. Barnes, R. G. Compton, E. Laborda, A. Molina, ChemistryOpen 2015, 4, 224.

[57] P. N. Barlett, Bioelectrochemistry: Fundamentals, experimental techniques and application, Wiley, Chichester, 2008.

[58] C. Leger, P. Bertrand, Chem. Rev. 2008, 108, 2379.

[59] F. A. Arsmstrong, Electrifying metalloenzymes in: Metalloproteins: Theory, calculations and experiments (A. E. Cho, W. A. Goddar III, eds), CRC Press, Taylor\&Francis Group, London, New York, 2015.

[60] F. A. Armstrong, Applications of voltammetric methods for probing the chemistry of redox proteins In : Bioelectrochemistry: Principles and practice (G. Lenaz, G. Milazz eds), Birkhauser Verlag AG, Basel, 1997.

[61] H. Salehzadeh, D. Nematollahi, Electrochim. Acta 2013, 111, 909.

[62] M. Rafiee, D. Nematollahi, H. Salehzadeh, Electrochim. Acta 2011, 56, 9946.

[63] D. Nematollahi, S. Hosseinzadeh, B. Dadpou, J. Electroanal. Chem. 2015, 759, 144.

[64] M. L. Olmstead, R. G. Hamilton, R. S. Nicholson, Anal. Chem. 1969, 41, 260.

[65] V. Mirceski, R. Gulaboski, I. Kuzmanovski, Bull. Chem. Technol. Macedonia 1999, 18, 57.

[66] R. Gulaboski, V. Mirceski, M. Lovric, J. Solid State Electrochem. 2019, 23, 2493. 


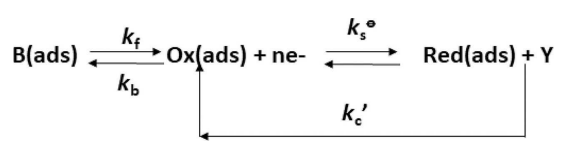

P. Kokoskarova, R. Gulaboski*

$1-13$

Theoretical Aspects of a Surface

Electrode Reaction Coupled with

Preceding and Regenerative

Chemical Steps: Square-wave Voltammetry of a Surface CEC'

Mechanism 